\title{
Correction to: A Teaching Experiment on a Knowledge-Network-Based Online Translation Learning Platform
}

\author{
Yuanyuan $\mathrm{Mu}$ and Wenting Yang
}

\section{Correction to: \\ Chapter "A Teaching Experiment on a Knowledge- Network-Based Online Translation Learning Platform" in: E. Popescu et al. (Eds.): Emerging Technologies for Education, LNCS 11984, https://doi.org/10.1007/978-3-030-38778-5_35}

The original version of this chapter was revised. The authors' affiliations were corrected to:

Yuanyuan $\mathrm{Mu}$

1. School of Foreign Studies, Hefei University of Technology, Hefei, China

2. Center for Translation Studies of Specialized Corpora, Hefei University of Technology, Hefei, China

Wenting Yang

3. School of Foreign Languages, Anqing Normal University, Anqing, China 